\title{
Heparin neutralization during collection and processing of blood inhibited by pyridoxal 5'- phosphate
}

Citation for published version (APA):

van Putten, J., van de Ruit, M., Beunis, M., \& Hemker, H. C. (1984). Heparin neutralization during collection and processing of blood inhibited by pyridoxal 5'-phosphate. Haemostasis, 14(3), 253-261. https://doi.org/10.1159/000215066

Document status and date:

Published: 01/01/1984

DOI:

10.1159/000215066

Document Version:

Publisher's PDF, also known as Version of record

\section{Please check the document version of this publication:}

- A submitted manuscript is the version of the article upon submission and before peer-review. There can be important differences between the submitted version and the official published version of record. People interested in the research are advised to contact the author for the final version of the publication, or visit the DOI to the publisher's website.

- The final author version and the galley proof are versions of the publication after peer review.

- The final published version features the final layout of the paper including the volume, issue and page numbers.

Link to publication

\footnotetext{
General rights rights.

- You may freely distribute the URL identifying the publication in the public portal. please follow below link for the End User Agreement:

www.umlib.nl/taverne-license

Take down policy

If you believe that this document breaches copyright please contact us at:

repository@maastrichtuniversity.nl

providing details and we will investigate your claim.
}

Copyright and moral rights for the publications made accessible in the public portal are retained by the authors and/or other copyright owners and it is a condition of accessing publications that users recognise and abide by the legal requirements associated with these

- Users may download and print one copy of any publication from the public portal for the purpose of private study or research.

- You may not further distribute the material or use it for any profit-making activity or commercial gain

If the publication is distributed under the terms of Article 25fa of the Dutch Copyright Act, indicated by the "Taverne" license above, 


\title{
Heparin Neutralization during Collection and Processing of Blood Inhibited by Pyridoxal 5'-Phosphate
}

\author{
Janjaap van Putten ${ }^{\mathrm{a}}$, Marjo van de Ruit ${ }^{\mathrm{a}}$, Marlène Beunis ${ }^{\mathrm{a}}, \mathrm{H}$. Coenraad Hemker ${ }^{\mathrm{b}}$ \\ a Department of Clinical Chemistry (Head: J.A.P. Stroes), Stichting Samenwerking Delftse Ziekenhuizen, \\ Delft, and ${ }^{b}$ Rijksuniversiteit Limburg, Maastricht, The Netherlands
}

Key Words. Heparin determination · Heparin neutralization · Pyridoxal phosphate . Heparin monitoring · Platelet inhibition · Blood sampling

Abstract. Spectrophotometric heparin assays are expected to be independent on clotting factors, either activated or nonactivated, but could be sensitive to heparin neutralization during blood collection. Is was shown that more than $200 \mathrm{U}$ of heparin/1 plasma can completely be neutralized during blood processing. Because the heparin neutralization is not constant but dependent on the sample as well as on the type of sample handling, one cannot beforehand compensate and correct the results for possible heparin neutralization. We tested the use of pyridoxal 5'-phosphate (PLP) to prevent heparin neutralization. As the use of PLP in the citrate tube decreased the heparin neutralization to a negligible effect, PLP-citrate tubes are to be preferred for all plasma heparin determinations.

\section{Introduction}

Heparin treatment is monitored by examining blood samples of treated patients. The activity of heparin can be estimated by coagulation tests $[1,2]$ or by amidolytic chromogenic substrate assays [3]. Clotting assays may show a large interindividual difference in heparin response $[4,5]$ and a large dependency on the reagents used $[6,7]$. The heparin concentration accurately measured by a chromogenic substrate assay is assumed to represent the heparin concentration in vivo. It is well known that the results of clotting assays could be influenced by activation of clotting factors and by neutralization of heparin during blood processing. Actions generally taken to ensure correct results are: rejecting the first volume of blood obtained, chilling and direct processing of the sample. Spectrophotometric heparin assays are expected to be independent on clotting factors, either activated or nonactivated, but could be sensitive to heparin neutralization [8]. 
Several measures were suggested to prevent release of heparin-neutralizing agents, notably platelet factor 4 (pf 4) [9-11]. Mixtures of drugs are used to prevent the release of pf 4 from thrombocytes [10-14]. Even then, special measures like direct processing of samples collected on melting ice are required.

The influence of the two-syringe method was investigated by determining the APTT, the antithrombin III (At-III) and the heparin concentration in the first tube and in the second tube of blood collected from patients on heparin therapy. The influence of blood storage and chilling of the centrifuge were each investigated by determining the heparin neutralization capacity of plasma differently manipulated.

As pyridoxal phosphate (PLP) has been reported to inhibit platelet functioning [15], we studied whether this drug could be used to prevent heparin neutralization. The experiments were repeated with PLP containing blood collection tuhes. The heparin concentration in plasma of the first PLP tube was compared with the heparin concentration in the generally used second citrate tube.

\section{Materials and Methods}

\section{Reagents}

Heparin: 5,000 USP $\mathrm{U} / \mathrm{ml}$ of the sodium salt (thromboliquine, Organon Teknika, Oss, The Netherlands). Dilutions were made with buffered saline (147 $\mathrm{m} M \mathrm{NaCl}, 6.52 \mathrm{mM} \mathrm{Na} \mathrm{HPO}_{4}, 1.62 \mathrm{mM} \mathrm{KH}{ }_{2} \mathrm{PO}_{4}$, $\mathrm{pH} 7.35$ ).

Thrombin (Roche, Basel, Switzerland), contained per vial 120 USP U bovine thrombin. The contents of each vial were dissolved in $2.4 \mathrm{ml}$ distilled water. Before use, 1 vol of thrombin was diluted with 5 vol of buffer.

Antithrombin III (KabiVitrum, Amsterdam, The Netherlands) contained $10 \mathrm{U} /$ vial. $1 \mathrm{U}$ is defined as the activity found in $1 \mathrm{ml}$ plasma. The contents of each vial were dissolved in $10 \mathrm{ml}$ distilled water and $100 \mu \mathrm{l}$ heparin $(2,500 \mathrm{U} / 1)$ were added to titrate the heparin neutralization effect [16].

Factor Xa (KabiVitrum): the contents of each vial (71 nkat) were dissolved in $10 \mathrm{ml}$ distilled water.

Chromogenic substrates: benz-Ile-Glu-Gly-Arg$\mathrm{pNA} \cdot \mathrm{HCl}$ (S-2222) and H-D-Phe-Pip-Arg-pNA.2 $\mathrm{HCl}$ (S-2238) (KabiVitrum), and Chromozym-Th (Boehringer-Mannheim, Amsterdam) were each dissolved in distilled water.

Buffer (pH 8.4 and I 0.2) contained di-Na-EDTA (7.5 mM), Tris- $\mathrm{HCl}(50 \mathrm{mM})$ and $\mathrm{NaCl}(175 \mathrm{mM})$.

APTT reagent: DiagenKaolin - platelet substitute from Diagnostic Reagents Ltd., Thame, Oxon, UK.

Pyridoxal $5^{\prime}$-phosphate was obtained from Merck, Darmstadt (Pyridoxal-5'-Phosphorsäureester-Mononatriumsalz $\left(\mathrm{C}_{8} \mathrm{H}_{9} \mathrm{NNaO}_{6} \mathrm{P} \cdot \mathrm{H}_{2} \mathrm{O}, \mathrm{MW} 269\right) .1 .346 \mathrm{~g}$ was dissolved in $20 \mathrm{ml}$ distilled water to obtain $0.25 \mathrm{M}$.

Citrate tube: $2.0 \mathrm{ml}$ Venoject tube (black stopper)

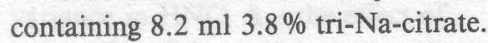

PLP tube: $50 \mu \mathrm{l} 0.25 \mathrm{M}$ PLP solution was added to a citrate tube after removing the stopper. The stopper was replaced and the original vacuum was restored by means of a vacuum pump. This tube used in a vacuum system, was filled to the same height as the original tube.

Sample procedure: blood was drawn from the antecubital vein by means of a vacuum system with a multisample needle. This sample is referred to as the first tube. Next, the second tube was drawn. Unless stated otherwise, samples were centrifuged for $10 \mathrm{~min}$ at $3,500 \mathrm{~g}$ at $15^{\circ} \mathrm{C}$. Plasmas thus obtained contained fewer than $3 \times 10^{9}$ platelets $/ 1$, and were stored at $-20^{\circ} \mathrm{C}$. The delay between venipuncture and centrifugation was less than $15 \mathrm{~min}$ for plasma pool as well as for specimens from outpatients. For inpatients this delay was $1 / 2-2 \mathrm{~h}$.

Pooled citrate plasma: contents of the second tubes of citrated plasmas from 31 donors were centrifuged twice at $3,500 \mathrm{~g}$ at $15^{\circ} \mathrm{C}$, subsequently mixed and stored at $-70^{\circ} \mathrm{C}$ in aliquots of $1 \mathrm{ml}$. The donors were laboratory workers, about as many males as females with a mean age of 30 years, healthy and using no drugs.

Pooled PLP plasma: the same procedure as described above was used to prepare a pool of PLP plasma, obtained in the first PLP tube from the same donors. 


\section{Assays}

Automated chromogenic heparin assays were performed on a Corona batch analyzer (Clinicon, Amsterdam) as described before [16] with S-2222 and factor $\mathrm{Xa}$, as well as with Chromozym-Th or S-2238 and thrombin. Reference samples were made of pooled citrate or PLP plasma spiked with known amounts of heparin of the same batch as we would determine. The calibration curve was a logarithmic fit through the reference measurements. The activated partial thromboplastin time (APTT) was performed as indicated by the manufacturer of the reagent, on a ' $\mathrm{KClO}$ ' coagulometer (Salm \& Kipp, Breukelen, The Netherlands). Plasma was incubated with the APTT reagent in a plastic tube. After recalcification the clotting time was measured.

\section{Heparin-Neutralizing Capacity (HNC)}

To determine the HNC, $100 \mathrm{U} / 1$ heparin were added to the PLP plasmas (in duplicate) at the predilution stage of the heparin assay. To the non-PLP plasmas, $200 \mathrm{U} / 1$ heparin were added. Anti-IIa activity of the heparin concentration was determined using a reference curve from 0 to $200 \mathrm{U} / \mathrm{l}$. The difference between the amount of heparin added and of heparin found was considered to indicate the amount of heparin neutralized (HNC). Therefore, the HNC of the pooled plasma used for reference measurements was zero by definition. Automated spectrophotometric AtIII assays were performed on the same analyzer, as described [16] with S-2222 and factor $\mathrm{Xa}$, as well as with Chromozym-Th or S-2238 and thrombin.

\section{Experimental Procedures}

Comparison of the First and Second Sample Tubes. Samples obtained from inpatients receiving heparin were processed as described above. Citrate plasmas obtained in the first and second tubes, both being nonPLP citrate tubes, were compared with regard to the APTT and to the anti-IIa and anti-Xa activities of heparin and At-III. Plasmas obtained in the first PLP tube and the second citrate tube were compared with regard to the anti-IIa and anti-Xa activity of heparin. PLP plasmas obtained in the first and second tubes from healthy laboratory workers and outpatients not receiving heparin were used to compare the HNC.

Influence of Delay on the HNC. Citrated blood was obtained from 20 outpatients not receiving heparin treatment. Blood from the first tube was distributed over two plastic tubes. One tube was centrifuged at $15^{\circ} \mathrm{C}$ within $15 \mathrm{~min}$ after sampling, whereas the other tube was centrifuged after leaving the blood for $5 \mathrm{~h}$ at room temperature. Plasmas were stored at $-20^{\circ} \mathrm{C}$ till HNC was determined. Reference samples for the HNC assay were made with pooled citrate plasma. This experiment was repeated with PLP-citrate plasma, obtained from another 20 outpatients not receiving heparin. In the HNC assay, reference samples made with PLP plasma were used.

\section{Statistics}

In the calculations of the relationship between two methods the experimental variance (determined in day-to-day reproducibility tests) of both methods was taken into account [17]. The influence of delay and of temperature control in the centrifuge on the HNC of plasma from first tubes was investigated in a balanced experiment, using paired samples of 20 patients. Experiments were designed to trace the components which were to influence the recovery of heparin: S e the random experimental error of the heparin determination, derived from earlier experiments; $\mathrm{S}$ i - the random inter-sample variance in $\mathrm{HNC}$; $\mathrm{A}$ - the effect of each type of sample handling; $\mathrm{S}$ i.a. - the composed, inter-sample effect of each type of sample handling.

The contribution of each component to the total variance of the HNC was analyzed. A hierarchical two-by-two analysis of variance (factor 1 = effect of sample handling; factor 2 = samples) was applied. Whether the influence of the process on the HNC is also sample dependent was revealed by this analysis as well. No effort was made to differentiate between interindividual and intervenipuncture variation. Both factors compose the intersample variation.

\section{Results}

The effect of the two-syringe technique was analyzed for the APTT, the heparin and At-III concentration (table I). The At-III concentrations in first and second tube citrate plasmas proved to be similar (fig. 1). The APTT of first tube citrate plasma was about $20 \%$ shorter than the APTT of second tube citrate plasma (fig. 2). About $12 \%$ of the anti-IIa (fig. 3) as well as anti-Xa (fig. 4) ac- 
Table I. Comparison of first and second citrate tubes

\begin{tabular}{|c|c|c|c|c|c|c|c|}
\hline Assay & Activity & $a$ & $\mathrm{~S}$ a & $b$ & $\mathrm{Sb}$ & $n$ & $r$ \\
\hline Heparin & anti-IIa 1 & $-6 \mathrm{U} / 1$ & $11 \mathrm{U} / 1$ & $0.88^{3}$ & 0.03 & 68 & 0.94 \\
\hline Heparin & anti-IIa ${ }^{2}$ & $-4 U / 1$ & $10 \mathrm{U} / 1$ & $0.88^{3}$ & 0.03 & 65 & 0.98 \\
\hline Heparin & anti-Xa & $-4 \mathrm{U} / 1$ & $14 \mathrm{U} / 1$ & $0.88^{3}$ & 0.03 & 65 & 0.93 \\
\hline At-III & anti-IIa ${ }^{1}$ & $-5 \%$ & $4 \%$ & $1.05 \mathrm{NS}$ & 0.05 & 69 & 0.91 \\
\hline At-III & anti-IIa ${ }^{2}$ & $-6 \%$ & $3 \%$ & $1.05 \mathrm{NS}$ & 0.04 & 69 & 0.92 \\
\hline APTT & & $4 \mathrm{~s}$ & $7 \mathrm{~s}$ & $0.77^{3}$ & 0.04 & 68 & 0.87 \\
\hline
\end{tabular}

Relationships $(y=a+b \cdot x)$ between results of first tube citrate plasma $(y)$ and results of second tube citrate plasma $(\mathrm{x})$. The standard deviation of intercepts $(\mathrm{S}$ a) as well as of the slopes $(\mathrm{S} b)$ are given. The last column shows the correlation coefficient ( $r$ ).

1 Substrate: S-2238.

2 Substrate: chromozym-Th.

3 The slope does differ significantly from $1.00(\mathrm{p}<0.005)$. NS = not significant.

tivities of heparin in first tube citrate plasmas appeared to be lost in comparison to those in second tube citrate plasmas.

The HNC were determined in citrate plasmas processed in well-defined conditions to analyze the contribution of the discrete steps to the heparin neutralization. It appeared that more than $200 \mathrm{U} / 1$ may be neutralized (table II). By analysis of variance it is found that the large variance in the $\mathrm{HNC}$ (e.g. $78 \mathrm{U} / 1$ ) is mainly due to the large intersample variance ( $\mathrm{S} \mathrm{i}=70 \mathrm{U} / \mathrm{l}$ ) and not to the relative small experimental variance $(\mathrm{Se}=15 \mathrm{U} / 1)$. The evident contribution of the composed intersample effect ( $\mathrm{S}$ i.a.) revealed that this effect was not constant, but significantly $(\mathrm{p}<0.001)$ dependent on the individual samples.

It was assumed that heparin neutralization during blood handling would be prevented if platelet activation could be inhibited. Platelet activation by ristocetin could be inhibited by small amounts of PLP. The PLP concentration used was limited by the extinction of PLP plasma during the measurement. We repeated the experiments described above with PLP specimens. From the results in table II, it is obvious that under the conditions tested the HNC of PLP tubes are far less than the HNC in citrate tubes. Moreover, the influence of sample handling is reduced enormously in the presence of PLP. Although for the PLP tubes a statistically significant influence of the sample handling method is still shown, the mean difference is of the same order as the experimental error and appeared to be independent on the individual samples $(\mathrm{S}$ i.a. $=\mathrm{NS})$. Also the large individual contributions to the total variances of the HNC in the citrate tubes ( 70 and $57 \mathrm{U} / 1)$ are reduced to clinically negligible values (18 and $9 \mathrm{U} / \mathrm{l})$ in the PLP tubes.

The heparin neutralization in PLP plasmas of second tubes of 31 healthy individuals appeared to be $26 \pm 16 \mathrm{U} / 1$ higher than in 
Fig. 1. Relationship between At-III concentrations in first tube citrate plasma (y-axis) and in second tube citrate plasma (x-axis), determined with the At-III assay (with chromozym-Th) based on IIa inactivation.

Fig. 2. Relationship between the APTT, determined in the first tube citrate plasma (y-axis) and in the second tube citrate plasma ( $\mathrm{x}$-axis).

Fig. 3. Relationship between anti-IIa (chromozym-Th) activity of heparin in the first tube citrate plasma (y-axis) and in the second tube ( $\mathrm{x}$-axis).
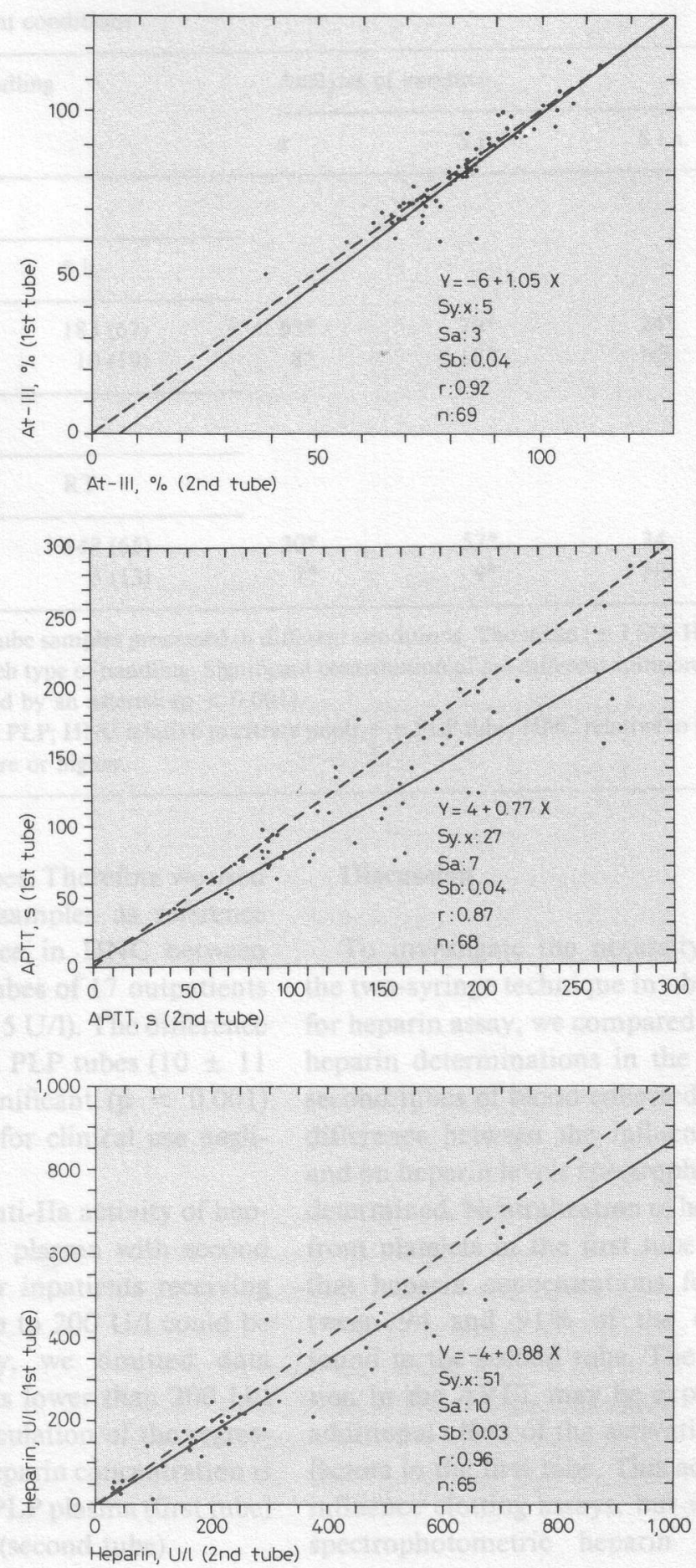
Table II. HNC in different conditions

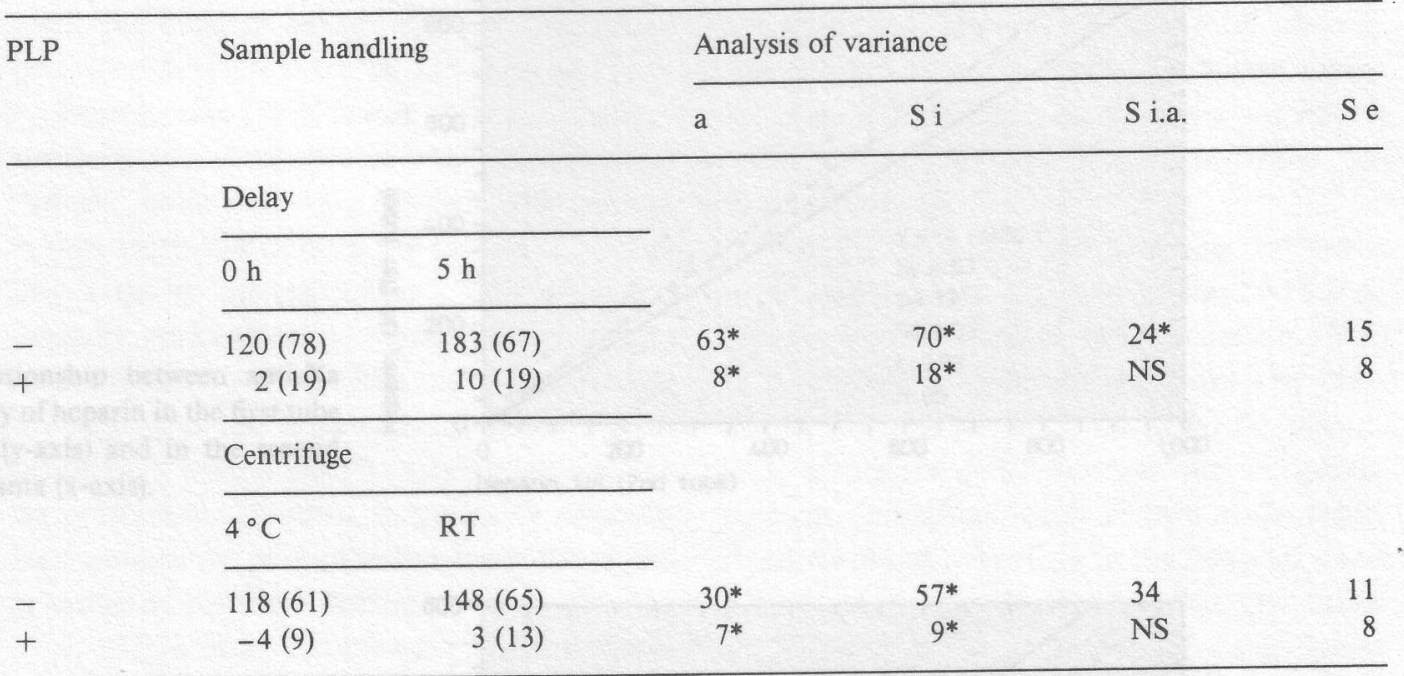

The HNC in U/l in first tube samples processed in different conditions. The mean ( $\pm 1 \mathrm{SD}) \mathrm{HNC}$ of 4 groups of 20 samples is given for each type of handling. Significant contribution of the different components to the total variance of HNC is indicated by an asterisk ( $p<0.001$ ).

- = Citrate tube without PLP; HNC relative to citrate pool; + = PLP tube; HNC relative to PLP pool; RT = nonchilled, room temperature or higher.

PLP plasmas of first tubes. Therefore we used a pool of these first samples as reference material. The difference in HNC between first and second PLP tubes of 17 outpatients is not significant $(5 \pm 15 \mathrm{U} / 1)$. The difference between first and third PLP tubes $(10 \pm 11$ $\mathrm{U} / \mathrm{l})$ is statistically significant $(\mathrm{p}<0.001)$ in a paired $t$ test, but for clinical use negligible.

We compared the anti-IIa activity of heparin in first tube PLP plasma with second tube citrate plasma for inpatients receiving heparin. As heparin up to $200 \mathrm{U} / 1$ could be neutralized completely, we omitted data points at heparin levels lower than $200 \mathrm{U} / 1$ PLP plasma in the calculation of the regression line (fig. 5). The heparin concentration is $72 \pm 23$ U/1 higher in PLP plasma (first tube) than in citrate plasma (second tube).

\section{Discussion}

To investigate the necessity of applying the two-syringe technique in obtaining blood for heparin assay, we compared the results of heparin determinations in the first and the second tubes of blood collected. We found a difference between the influence on APTT and on heparin levels spectrophotometrically determined. Neutralization of heparin by $\mathrm{pf} 4$ from platelets in the first tube may explain that heparin concentrations found are between 94 and $91 \%$ of the concentration found in the second tube. The larger deviation in the APTT may be explained by the additional effect of the activation of clotting factors in the first tube. This activation does influence clotting assays, but will not affect spectrophotometric heparin assays. This 
Fig. 4. Relationship between anti-Xa (S-2222) activity of heparin in the first tube citrate plasma (y-axis) and in the second tube citrate plasma ( $\mathrm{x}$-axis).

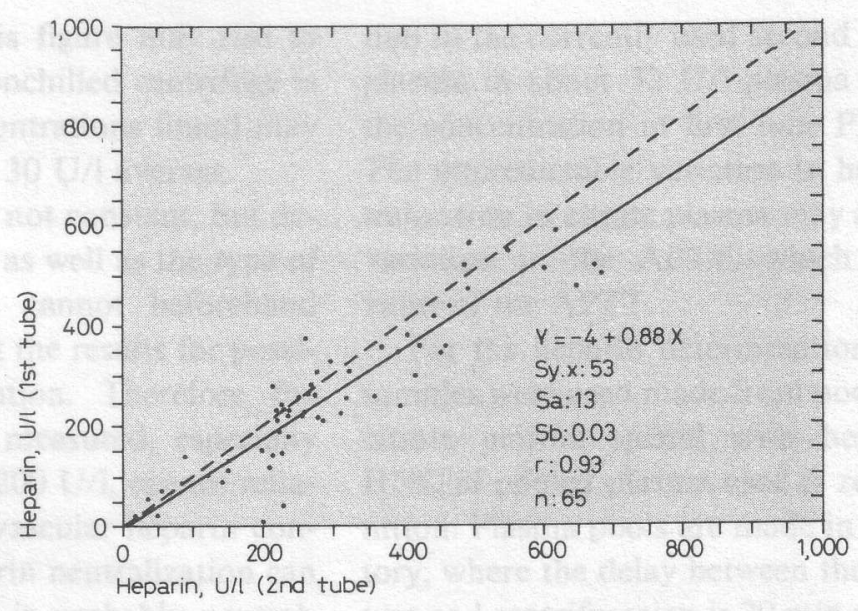

Fig. 5. Relationship between anti-IIa (S-2238) activity of heparin in first tube PLP plasma (y-axis) and in second tube citrate plasma (x-axis). Only data points with more than 200 U/1 PLP plasma are shown.

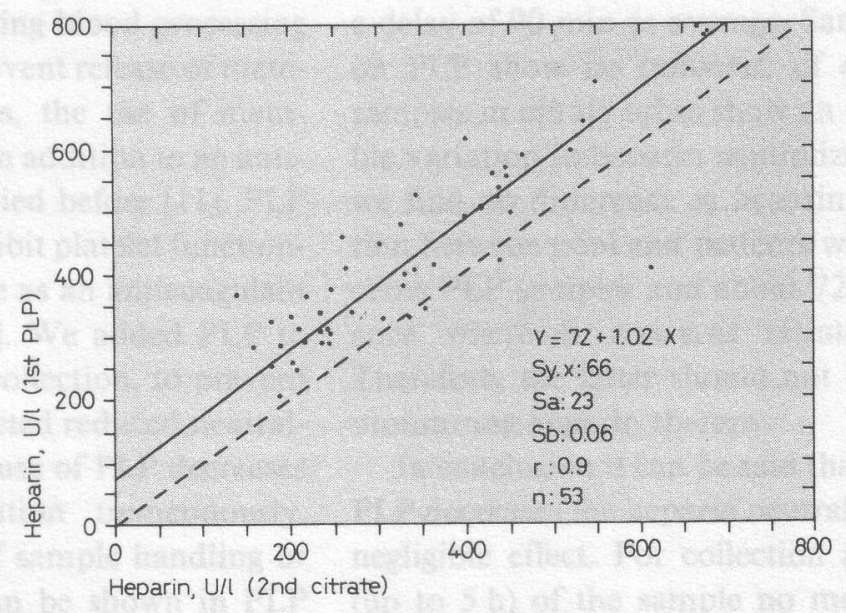

again illustrates that the APTT cannot be used to quantify validly heparin concentrations. It is clear that less heparin is recovered in the first tube than in the second tube. The difference in heparin concentrations cannot be explained by a difference in At-III concentration, as At-III concentrations of both tubes were the same (fig. 1). The degree of heparin neutralization induced by various sample handling procedures was further investigated with the pooled, promptly processed and chilled second tube samples as a standard. The HNC appeared to be $120 \pm 78$ $\mathrm{U} / 1$ in the first tube. If first tubes are used for heparin determination, the heparin concentration found will be lowered by $120 \mathrm{U} / 1$ average. As delay in processing the blood after venipuncture cannot always be avoided 
in routine practice, this figure may rise to above $180 \mathrm{U} / 1$. If a nonchilled centrifuge is used, the heparin concentrations found may be lowered by an extra $30 \mathrm{U} / 1$ average.

Because the HNC is not constant, but dependent on the sample as well as the type of sample handling, one cannot beforehand compensate and correct the results for possible heparin neutralization. Therefore the heparin concentration measured, especially in the range from 0 to $200 \mathrm{U} / 1$, cannot reliably represent the intravascular heparin concentration, unless heparin neutralization can be prevented. Heparin is probably neutralized mainly by pf 4 released from the alpha granules of platelets during blood processing $[8,9,18]$. In order to prevent release of material from these granules, the use of membrane-stabilizing drugs in addition to an anticoagulant has been studied before [11]. PLP has been reported to inhibit platelet functioning [15] and even its use as an anticoagulant has been described [19]. We added PLP to citrate tubes for blood collection, to prevent release of pf 4 and expected reduced neutralization of heparin. The use of PLP decreases the heparin neutralization tremendously. Hardly any influence of sample handling or intersample variance can be shown in PLP tubes in comparison to the large influences on the HNC in citrate tubes. Based on the results of the HNC tests we consider the PLP tubes superior to the citrate tubes in blood collection for heparin determination. Presumably as a result of the longer period of increased pressure applied by the tourniquet used, the HNC is little higher in the second or third than in the first tube of blood collected from the same venipuncture wound. This phenomenon suggests an advantage of using the first tube rather than the second for heparin determination. The heparin concentra- tion in the currently used second tube citrate plasma in about $72 \mathrm{U} / 1$ plasma lower than the concentration in first tube PLP plasma. The unpredictable variation in heparin neutralization in citrate plasma may also cause a variation in the APTT, which limits the value of the APTT.

For the heparin determination, reference samples were used made from pooled PLP or citrate plasma spiked with heparin. The HNC of pooled plasma used is zero by definition. Plasma pools are made in the laboratory, where the delay between the venipuncture and centrifugation is $20 \mathrm{~min}$ at the most. Routine blood collection in the hospital takes a delay of $90 \mathrm{~min}$ as average. Samples taken on PLP show no influence of delay while samples in citrate tubes show an unpredictable variation in heparin neutralization. Thus we find no difference in heparin concentration between pool and patients where it concerns PLP samples and about 72 U/1 difference where it concerns citrate samples. Therefore, the latter should not be used for monitoring heparin therapy.

In conclusion it can be said that the use of PLP decreases the heparin neutralization to a negligible effect. For collection and storage (up to $5 \mathrm{~h}$ ) of the sample no melting ice is necessary. The possibility of using the first tube implies that only one tube needs to be drawn for heparin determination. The use of PLP in the citrate tube for blood collection is preferred for all plasma heparin determinations.

\section{Acknowledgements}

The authors wish to acknowledge the significant and helpful extra work offered by the co-workers of the three 'sublaboratoria', in order to provide us with blood samples. 


\section{References}

1 Pizutto, J.; Garcia-Medez, S.; Paz Reyna, M. de la; Morales, R.; Aviles, A.; Zavala, B.; Gaos, C.: Thrombin time dilution test: a simple method for the control of heparin therapy. Thromb. Haemostasis 42: 1276-1285 (1979).

2 Hoffman, J.J.M.L.; Meulendijk, P.N.: Heparin: a simple, one sample determination of both effect and concentration based on the activated partial thromboplastin time. Clinica chim. Acta 87: 417424 (1978).

3 Teien, A.N.; Lee, M.; Abildgaard, U.: Assay of heparin using a chromogenic substrate for activated factor X. Thromb. Res. 8: 413-416 (1976).

4 Putten, J.J. van; Ruit, M. van de; Beunis, M.; Hemker, H.C.: Inter-individual variation in relationships between plasma heparin concentration and the results of five heparin assays. Clinica chim. Acta 122: 261-270 (1982).

5 Whitfield, L.R.; Levy, G.: Relationship between concentration and anticoagulant effect of heparin in plasma of normal subjects: magnitude and predictability of interindividual difference. Clin. Pharm. 28: 509-516 (1980).

6 Teien, A.N.; Lie, M.: Heparin assay in plasma; a comparison of five clotting methods. Thromb. Res. 7: 777-778 (1975).

7 Thomson, J.M.: The control of heparin therapy by the activated partial thromboplastin time: results of collaborative studies. Scand. J. Haematol. 25: suppl. 37, pp. 73-83 (1980).

8 O'Brien, P.F.: The chromogenic assay of low levels of heparin in plasma: probable effect of platelets. Thromb. Haemostasis 48: 69 (1980).

9 Teien, A.N.; Lie, M.: Evaluation of an amidolytic heparin assay method: increased sensitivity by adding purified antithrombin III. Thromb. Res. 10: 399-410 (1977).

10 Thomson, J.M.: Blood coagulation and haemostasis; 2nd ed., p. 308 (Churchill Livingstone, Edinburgh 1980).
11 Prowse, C.; Pepper, D.; Dawes, J.: Prevention of platelet alpha-granule release reaction by membrane-active drugs. Thromb. Res. 25: 219-227 (1982).

12 Boer, A.C. de; Butt, R.; Turpie, A.G.G.; Genton, E.: The use of the evacuated blood collection tube in the determination of plasma beta-thromboglobulin. Thromb. Res. 20: 693-695 (1980).

13 Files, J.C.; Malpass, T.N.; Yee, E.K.; Ritchie, J.L.; Harker, L.A.: Studies of human platelet alphagranule release in vivo. Blood 58: 607-618 (1981).

14 Ottolander, G.J.H. den: Hemostase en trombose, p. 90 (Bunge, Utrecht 1979).

15 Kornecki, E.; Feinberg, H.: Pyridoxal phosphate inhibition of platelet function. Am. J. Physiol. 238: H54-H60 (1980).

16 Putten, J.J. van; Ruit, M. van de; Beunis, M.; Hemker, H.C.: Automated determination of heparin with chromogenic substrates. Haemostasis 14: 179-183 (1984).

17 Davies, O.; Goldsmith, P.L.: Statistical methods in research and production; 4th ed. (Longman, London 1:76;:

18 Dawes, J.; Pumphrey, C.W.; McLaren, K.M.; Prowse, C.V.; Pepper, D.S.: The in vivo release of human platelet factor 4 by heparin. Thromb. Res. 27: 65-76 (1982).

19 Editorial: Is vitamin $B_{6}$ an antithrombotic agent? Lancet ii: 1299-1301 (1981).

Received: September 3, 1983

Accepted in revised form by editor

J.C.W. van de Loo: February 7, 1984

M.H. Beunis,

Department of Clinical Chemistry,

SSDZ,

PO Box 5010,

2600 GA Delft (The Netherlands) 